www.jmscr.igmpublication.org

Index Copernicus Value: 79.54

ISSN (e)-2347-176x ISSN (p) 2455-0450

crossref DOI: https://dx.doi.org/10.18535/jmscr/v7i6.50

\title{
A Prospective Study to Compare Concomitant Boost Radiotherapy and Conventional Radiotherapy in Oral Cavity Cancer
}

\author{
Authors \\ Shekhar Anand ${ }^{*}$, S.N. Prasad ${ }^{2}$ \\ ${ }^{1}$ Resident, ${ }^{2}$ Professor and Head, G.S.V.M. Medical College, Kanpur, Uttar Pradesh, India \\ *Corresponding Author \\ Shekhar Anand
}

\begin{abstract}
Background: India accounts for the highest incidence of oral and oropharyngeal cancers. For early stages, chemoradiotherapy or surgery are equally effective. For advanced stages require multimodality treatment. Standard chemoradiotherapy requires $2 G y$ per fractios, 5 fractions per week for 7 weeks. Accelerated repopulation sets in the $4^{\text {th }}$ week of conventional radiation. To offset this effect, concomitant boost radiotherapy may be used. This study was designed to compare prospectively conventional chemoradiotherapy with concomitant boost chemoradiotherapy.

Materials and Methods: Total 60 patients (30 for Arm A-conventional chemoradiation and 30 for Arm $B$ - concomitant Boost) were selected from the cross section of patients registered at the J. K. cancer institute and other associated hospitals of G. S. V. M Medical College, Kanpur from December 2016 to August 2018. Histologically proven carcinoma patients by way of biopsy were evaluated. The data thus obtained were assessed, analyzed and compared to find out difference in all the groups in terms of tumor response and quality of life by using t test.

Results: Out of 30 patients, in Arm A, 13 (43.33\%) and in Arm B, 12 patients (40\%) had complete response (CR) and the rest of the patients had partial response except for 3 patients and 4 patients in Arm $A$ and 5 patients and 4 patients in Arm B they had stable disease progressive disease respectively.

Conclusion: Concomitant boost radiotherapy with concomitant cisplatin has a response comparable to the conventional chemoradiotherapy regimen with not significantly higher cases of oral mucositis. CBT is easily tolerated by patients, with slight enhancement in acute reactions and so far has given much better results as compared to conventional RT alone.

Keywords: Concomitant Boost, Chemoradiotherapy, Mucositis, Oral Cavity, Oropharyngeal Cancers.
\end{abstract}

\section{Introduction}

Head and neck cancer is the sixth most common type of cancer in the world, more than 2 lakh new cases of head and neck cancer are diagnosed each year. India contributes to up to $7.8 \%$ of the global cancer burden and $8.33 \%$ of global cancer deaths. ${ }^{[1]}$ India accounts for the highest incidence of oropharyngeal cancer in the world with over $1,00,000$ cases registered annually. ${ }^{[2]}$ In head and neck cancers, the chemoradiotherapy has been identified as a standard therapeutic method in. ${ }^{[3-4]}$ Work of Maciejewski ${ }^{[5]}$ and Withers ${ }^{[6]}$, showed that with increasing overall time the total dose to cure a tumour of the head and neck area had to be 
raised, this was attributed to repopulation, which may not be important until the third week of a course of treatment. Accelerated regimens with shortened overall duration of treatment were therefore investigated with the aim of reducing the time in which cellular repopulation could occur. Several randomised clinical trials have shown an increase in local control using accelerated or hyperfractionated radiotherapy. ${ }^{[7-10]}$ A metaanalysis showed that altered radiotherapy with new fractionating schedules, achieved an increase of $7 \%$ in local control and $3 \%$ in survival at 5 years. ${ }^{[11]}$

Several studies have attempted to determine the dose of radiation necessary to overcome the effects of tumor regeneration. Withers et al analyzed the dose equivalent of regeneration during therapy. They suggested that tumor clonogens undergo an accelerated repopulation after a certain period of time, and that an additional $0.6 \mathrm{~Gy}$ is required for each day of therapy beyond the time when repopulation sets in. ${ }^{[12]}$ It was estimated that this phenomenon of accelerated repopulation begins in the fourth week of a conventionally fractionated schedule, based on a retrospective analysis of local control rates in tonsillar carcinomas achieved at different international centers using a variety of fractionation schedules. ${ }^{[13]}$ Unfortunately, simply adding this supplementary dose to overcome repopulation could potentially increase late effects on normal tissue. An alternative method was to shorten the time of therapy to prohibit accelerated repopulation from occurring. Multiple fractions per day might not be required if one could deliver larger doses per fraction to the tumor only, while maintaining lower doses per fraction to subclinical disease and normal tissues. Butler and colleagues have described an initial experience with this approach, with encouraging results that warrant further study. ${ }^{[14]}$ Two randomized trials, in Denmark $^{[15]}$ and Poland, ${ }^{[16]}$ evaluated conventional therapy with five fractions per week, compared to accelerated regimens using six to seven fractions per week. Total dose and fraction size remained the same, resulting in a shortening of treatment time by 1 or 2 weeks. In Vancouver, Canada, Jackson and associates attempted a greater reduction in overall treatment time, delivering 66 Gy in 33 fractions in either 45 to 48 days or 22 to 25 days. ${ }^{[17]}$

Radiation for head and neck cancers involves delivery of both a planned dose to the gross tumor and a lesser dose to sites of microscopic or subclinical disease. Conventional radiation delivers 50 to 54 Gy to these subclinical sites, and then the radiation portals are reduced in size to deliver the "boost" to the gross disease. Concomitant-boost therapy delivers this boost on the same days that the therapy to subclinical disease is given. Concomitant boost radiotherapy (CBT) despite being a variant of accelerated fractionation, is associated with minimal increase of acute reactions because it uses the concept of accelerated fractionation while minimizing the volume of tissue that is irradiated with high doses. Altered fractionation has also been used in breast cancer cases with acceptable quality of life and local control. ${ }^{[27]}$

\section{Materials and Methods}

This study acrued a total of 60 patients (30 for Arm A- conventional chemoradiation and 30 for Arm B- concomitant Boost) registered in the J. K. cancer institute, Kanpur from December 2016 to August 2018. The eligibility criteria included histopathologically confirmed squamous cell carcinoma of the oral cavity.

Patients acrued for study underwent pretreatment evaluation which included complete history, physical examination, complete systemic examination. Patients were assessed their general condition by KPS and BSA. Their hematological assessment was done by complete hemogram, biochemical assessment of kibney and liver function, radiological assessment. Dental assessment and care. Patients were staged according to AJCC staging system.

Based on the above assessment the patients for the study were selected depending on Histologically 
proven cases of Carcinoma, Karnofsky Performance Status > 70, early and locally advanced oral cavity cancer.

Complete hemogram with $\mathrm{Hb}>10 \mathrm{gm} / \mathrm{dL}$; TLC4000 to $11000 / \mathrm{cmm}$, Platelet count $>100,000 / \mathrm{cmm}$. Renal function tests with Blood urea $<40 \mathrm{mg} / \mathrm{dL}$ and Serum creatinine $<1.5 \mathrm{mg} / \mathrm{dL}$. Liver function tests with SGOT < 35 IU/L and SGPT < 40 IU/L. Patients who sign the informed consent and are ready to be on follow up as required

The patients having any of the following conditions were excluded from the study:

Prior radiation, surgery or chemotherapy for the disease, poor general condition with Karnofsky Performance Status of $<70$,pregnant or lactating patient, associated medical condition such as renal disease, liver disease or heart disease

And thus the patients fulfilling the Inclusion criteria and exclusion criteria were randomized into two Arms as followed:

Arm A: Received RT as conventional fractionation (200cGy per fraction), 5 days a week, shrinking the field anterior to the cord after 46 Gy. A total of 70 Gy was given with concurrent Inj. Cisplatin 100mg/m2 3weekly.

Arm B: Received RT in the form of concomitant boost. In this group, the large field was given 45 Gy(1.8 Gy per fraction) daily for 5 days a week for 5 weeks. The remaining $27 \mathrm{~Gy}$ were given as boostin 15 fractions to the small field at an interval of $6 \mathrm{hrs}$ in the first 3 weeks of treatment. A total of 72 Gy was given with concurrent Inj. Cisplatin $100 \mathrm{mg} / \mathrm{m} 23$ weekly.

From the commencement of treatment, all the patients included in the study were carefully and regularly assessed weekly during treatment.

Radiation reactions were assessed by Radiation Therapy Oncology Group (RTOG) criteria. Tumor response (both primary and nodal response) were assessed by RECIST (1.1) response criteria 2 months after completion of Radiotherapy.

The major study endpoints were tumor response, acute and late toxicities and quality of life using
University of Washington quality of life questionnaire version 4.0

All the patients were assessed two weeks after the completion of treatment, to detect acute complications like mucositis, skin reaction, late reactions based on RTOG criteria .Patients were followed monthly upto a minimum of 6 months . Tumor response was assessed based on RECIST response criteria1.1

All the patients were followed up regularly on OPD basis for a period of at least 6 months, once every month after completion of the treatment.

At every visit, each patients were clinically evaluated for local control of disease and treatment related complications. The patients were assessed for any evidence of distant metastasis during each follow up. On suspicion of any local recurrence, biopsy were taken for histopathology and correlated clinically. The QOL were assessed at the beginning of treatment, on the day of completion of treatment and one month after completion of planned treatment using University of Washington QOL questionnaire.

The data thus obtained was assessed, analyzed and compared to find out difference in all the groups in terms of tumor response and quality of life by using student $t$ test.

\section{Results}

Total number of patients identified for the trial based on inclusion and exclusion criteria were randomized to arm A and arm B. All patients in both arm completed the assigned treatment.

Table 1: Shows distribution of patients into two groups.

\begin{tabular}{|l|c|c|c|}
\hline \multirow{2}{*}{ Sex } & Parameter & $\begin{array}{c}\text { Arm A } \\
(\mathrm{n}=30)\end{array}$ & $\begin{array}{c}\text { Arm B } \\
(\mathrm{n}=30)\end{array}$ \\
\hline Median Age & Male & 27 & 23 \\
\hline \multirow{4}{*}{ Residence } & Female & 3 & 7 \\
\cline { 2 - 4 } & Rural & 40 years & 40 years \\
\cline { 2 - 4 } & Urban & 16 & 13 \\
\hline Site & Total & 30 & 17 \\
\cline { 2 - 4 } & Tongue & 11 & 30 \\
\cline { 2 - 4 } & Alveolus & 4 & 3 \\
\cline { 2 - 4 } & Buccal mucosa & 13 & 15 \\
\cline { 2 - 4 } & RMT & 2 & 1 \\
\cline { 2 - 4 } & GBS & 0 & 1 \\
\cline { 2 - 4 } & Hard Palate & 0 & 1 \\
\hline Stage & II & 6 & 7 \\
\cline { 2 - 4 } & III & 13 & 11 \\
\cline { 2 - 4 } & IV & 11 & 12 \\
\hline
\end{tabular}


In our study age wise distribution in both arms were maximum in age group 31 to 40 years. The median of age of both groups were 40 years. Chisquare $=1.19$, degrees of freedom $=3, \mathrm{P}$ value $=$ 0.755 , not significant. Sex wise distribution in both arms were maximum in male. Chi-square = 1.92 , $\mathrm{df}=1, \mathrm{P}$ value $=0.166$, not significant . Residence wise distribution in Arm A was more in rural i.e. $16(53.33 \%)$ than in urban i.e. 14 (46.67\%). However in Arm B was more in urban $17(56.67 \%)$. Chi-square $=0.601, \mathrm{df}=1, \mathrm{P}$ value $=$ 0.438 , not significant. In our study, maximum involvement of the site were buccal mucosa followed by tongue. Chi-square $=2.82, \mathrm{df}=5, \mathrm{P}$ value $=0.728$, not significant. Our study showed stages of cancer in patient of Arm A was more is stage third i.e. 13 (43.33\%), followed by stage fourth i.e. $11(36.67 \%)$, stage second were 6 (20\%). However in Arm B maximum were stage fourth $12(40 \%)$, followed by stage third 11 (36.67\%), stage second were 7 (23.33\%). However no patient of Arm A or Arm B was found in stage first. Chi-square $=0.373, \mathrm{df}=2, \mathrm{P}$ value $=0.830$, not significant. [Table 1]

Table 2: Shows histological differentiation

\begin{tabular}{|l|l|c|c|c|c|}
\hline \multirow{2}{*}{ Characteristics } & \multicolumn{2}{c|}{ Arm A } & \multicolumn{2}{c|}{ Arm B } \\
\cline { 3 - 6 } \multicolumn{2}{|c|}{} & No. & \% & No. & \% \\
\hline $\begin{array}{l}\text { Histological } \\
\text { differentiation }\end{array}$ & Well & 17 & 56.67 & 19 & 63.33 \\
\cline { 2 - 6 } & Moderate & 10 & 33.33 & 7 & 23.33 \\
\cline { 2 - 6 } & Poor & 3 & 10 & 4 & 13.33 \\
\hline \multicolumn{2}{|c|}{ Total } & 30 & 100 & 30 & 100 \\
\hline
\end{tabular}

In our study histological differentiation in Arm A were well differentiated i.e. $56.67 \%$, moderate $33.33 \%$ and poor was $10 \%$. However in Arm B, well differentiated were $63.33 \%$, followed by moderate $23.33 \%$ and poor $13.33 \%$. [Table 2]

Table 3: Shows duration of treatment and skin, mucosal reaction.

\begin{tabular}{|l|c|c|c|}
\hline \multicolumn{2}{|l|}{} & Arm A & Arm B \\
\hline \multicolumn{2}{|l|}{ Duration of treatment } & $49-72$ days & $35-70$ days \\
\hline \multicolumn{2}{|l|}{ No. of Chemo } & $1-3$ & $0-3$ \\
\hline Dermatitis & I & 19 & 13 \\
\cline { 2 - 4 } & II & 6 & 12 \\
\cline { 2 - 4 } & III & 5 & 5 \\
\hline \multirow{3}{*}{ Mucositis } & I & 4 & 0 \\
\cline { 2 - 4 } & II & 26 & 18 \\
\cline { 2 - 4 } & III & 0 & 12 \\
\hline Ryle`s tube & 1 patient & 3 patients \\
\hline
\end{tabular}

Our study showed that the duration of the treatment was 49 to 72 days in Arm A however 35 to 70 days in Arm B and number of chemotherapy 1-3 in Arm A and 0-3 in Arm B. In Arm A the dermatitis I was $63.33 \%$, II was $20 \%$ and III was $16.67 \%$ in comparison to Arm B the I was $43.33 \%$, II was $40 \%$ and third was $16.67 \%$. In Arm A the mucositis I was $13.33 \%$, II $86.67 \%$ and III was $0 \%$ in comparison to Arm BI was $0 \%$, II was $60 \%$ and III was $40 \%$. Ryle's tube in Arm A was one patient and in Arm B 3 patients. [Table 3]

Table 4: Shows response of the treatment

\begin{tabular}{|l|l|l|l|l|}
\hline \multirow{2}{*}{ Response } & \multicolumn{2}{|l|}{ Arm A } & \multicolumn{2}{l|}{ Arm B } \\
\cline { 2 - 5 } & No. & \% & No. & \% \\
\hline Complete response (CR) & 13 & 43.33 & 12 & 40 \\
\hline Partial response (PR) & 10 & 33.33 & 9 & 30 \\
\hline Stable disease (SD) & 3 & 10.00 & 5 & 16.67 \\
\hline Progressive disease (PD) & 4 & 13.33 & 4 & 13.33 \\
\hline Total & 30 & 100 & 30 & 100 \\
\hline
\end{tabular}

Our study showed the response of the treatment in Arm A $43.33 \%$ showed complete response, $33.33 \%$ showed partial response, $10 \%$ showed stable disease and $13.33 \%$ showed progressive disease in comparison to Arm B 40\% showed complete response, $30 \%$ showed partial response, $16.67 \%$ showed stable disease and $13.33 \%$ showed progressive disease. Chi-square $=1.91$, df $=3, \mathrm{P}$ value $=0.591$. [Table 4$]$

Table 5: Post treatment most common complication

\begin{tabular}{|l|l|l|l|l|}
\hline & \multicolumn{2}{|l|}{ Arm A } & \multicolumn{2}{l|}{ Arm B } \\
\cline { 2 - 5 } & No. & $\mathbf{\%}$ & No. & \% \\
\hline Dryness of mouth & 17 & 56.67 & 15 & 53.33 \\
\hline Pain & 6 & 20 & 0 & 0 \\
\hline Loss of taste & 1 & 3.33 & 5 & 16.67 \\
\hline Neck lymphedema & 2 & 6.67 & 4 & 13.33 \\
\hline Trismus & 2 & 6.67 & 4 & 13.33 \\
\hline Disphagia & 2 & 6.67 & 2 & 6.67 \\
\hline
\end{tabular}

Our study showed post treatment most common complications in Arm A was dryness of mouth $56.67 \%$, followed by pain $20 \%$, trismus $6.67 \%$ and dysphagia $6.67 \%$ and loss of taste $3.33 \%$ in comparison to Arm B dryness of mouth 53.33\%, followed by loss of taste $16.67 \%$, neck lymphedema $13.33 \%$, decreased mouth opening $13.33 \%$ and difficulty in swallowing $6.67 \%$. [Table 5] 
Table 6: Disease free survival, duration of follow up and status on last follow up.

\begin{tabular}{|l|c|c|c|}
\hline \multicolumn{2}{|l|}{} & Arm A & Arm B \\
\hline \multicolumn{2}{|l|}{ Disease free survival } & $\begin{array}{c}(2-24) \\
\text { Average }=12\end{array}$ & $\begin{array}{c}(3-20) \\
\text { Average }=8\end{array}$ \\
\hline \multicolumn{2}{|l|}{ Duration of follow up } & $\begin{array}{c}(6-24) \\
\text { Average }=15\end{array}$ & $\begin{array}{c}(6-24) \\
\text { Average }=8\end{array}$ \\
\hline Status on last follow up & NAD & 19 & 21 \\
\cline { 3 - 4 } & Salvage chemo & 7 & 7 \\
\cline { 2 - 4 } & BSC & 4 & 2 \\
\hline
\end{tabular}

Our study showed disease free survival in Arm A was 2-24 (average 12) and in Arm B 3-20 (average 8). Duration of follow up in Arm A was 6-24 (average 15) and in Arm B 6-24 (average 8). Status on last follow up was in Arm A- NAD 19, salvage chemo 7 and BSC 4 and in Arm B NAD 21, salvage 7 and BSC 2. [Table 6]

\section{Discussion}

Concomitant boost radiotherapy was taken in the study keeping in mind the radiobiological aspects of accelerated fractionated radiotherapy. ${ }^{[20]}$ Concomitant boost radiotherapy has shown a better response than conventionally fractionated radiotherapy in various studies done. ${ }^{[18-19,21-23]}$ Most successful treatment schedules attempt to administer the highest possible doses during the shortest possible time without doing much damage to the normal tissues and vital organs at risk. Concomitant boost radiotherapy has been tried keeping in mind the radiobiological aspects of accelerated fractionation $\mathrm{RT}^{[20]}$, which gives beneficial results by decreasing the number of clonogen cells to a considerable extent and without doing much harm to the normal cells ${ }^{[24]}$. The concomitant boost technique of administering twice daily radiation therapy during only part of the treatment course allows for an aggressive fractionation schedule and limits the volume of normal mucosa exposed to twice daily radiation therapy. The significance of accelerated repopulation in conventionally irradiated head and neck tumors has been reported ${ }^{[23-24]}$. The isoeffective dose for tumor control significantly increases after 30 treatment days. Most successful treatment schedules attempt to administer the highest possible doses during the shortest time tolerable to early and late responding normal tissues.

Prolonged treatment time, for the purpose of this study was defined as completing treatment with a delay of more than 5 days. Patients who were able to complete their treatment within the stipulated time plus a 5 day allowance for logistical problems and public holidays were considered to have completed on time. Similar results were seen in the study by Rishi A, Ghoshal S et al. where $74 \%$ patients in concomitant boost arm showed complete response as compared to $68 \%$ patients in chemoradiotherapy arm and the difference was statistically insignificant. ${ }^{[25]}$ In a study by $\mathrm{K}$ Shrivastava, M Shrivastava et $\mathrm{al}^{[26]}$, out of 40 patients, 30 patients $(75 \%)$ in concomitant boost arm and 24 patients $(60 \%)$ in conventional chemoradiotherapy arm had complete response and the rest of the patients had partial response except for one patient in chemoradiotherapy arm who showed no response. The follow-up of the present study was relatively short and prevents us from commenting on the long term disease free survival, overall survival, and a more comprehensive evaluation of the late toxicities too. Another limitation of our study was the relatively smaller sample size and consequently, subgroup analyses could not be done.

\section{Conclusion}

The observations made in our study helped us arrive at a conclusion that concomitant boost radiotherapy with concomitant cisplatin has a response comparable to the conventional chemoradiotherapy regimen with not significantly higher cases of oral mucositis. But the need of the hour is that studies with larger sample sizes and longer follow-up should be instituted for further validation of the feasibility of concomitant boost radiotherapy and to get significant results so that we are able to consider concomitant boost radiotherapy as a routine practice in treatment of locoregionally advanced oral cavity and oropharyngeal carcinomas in future. 


\section{References}

1. Saranath D, khanna A. Current status of cancer burden; global and Indian scenario. Biomed Res J. 2014;1:1-5.

2. M.I. Saunders et al. Head and Neck Cancer: Altered Fractionation Schedules. The Oncologist. 1999;4:11-16.

3. Krstevska V. Radiotherapy and chemotherapy in locally advanced head and neck squamous cell carcinoma. J BUON. 2009;14:361-73.

4. Fu KK. Biological basis for the interaction of chemotherapeutic agents and radiation therapy. Cancer. 55:2123.1985.

5. Maciejewski B, Preuss-Bayer G, Trott KR. The influence of the number of fractions and overall treatment time on local control and late complication rate in squamous cell carcinoma of the larynx. Int J Radiat Oncol Biol Phys. 1983;9:321-328.

6. Withers, H.R., Taylor, J.M., Maciejewski, B. The hazard of accelerated tumor clonogen repopulation during radiotherapy ActaOncol. 1988;27:131-146.

7. Pinto, L.H., Canary, P.C., Araujo, C.M., Bacelar, S.C., Souhami, L. Prospective randomized trial comparing hyperfractionated versus conventional radiotherapy in stages III and IV oropharyngeal carcinoma. Int J Radiat Oncol Biol Phys. 1991;21:557-562.

8. Horiot, J.C., Le Fur, R., N'Guyen, T. et al, Hyperfractionation versus conventional fractionation in oropharyngeal carcinoma: final analysis of a randomized trial of the EORTC cooperative group of radiotherapy. Radiother Oncol. 1992;25:231-241.

9. Fu, K.K., Pajak, T.F., Trotti, A. et al, A radiation therapy oncology group (RTOG) phase III randomized study to compare hyperfractionation and two variants of accelerated fractionation to standard fractionation radiotherapy for head and neck squamous cell carcinomas: first report of RTOG 9003.Int J Radiat Oncol Biol Phys. 2000;48:7-16.

10. Overgaard, J., Hansen, H.S., Specht, L. et al, Five compared with six fractions per week of conventional radiotherapy of squamous-cell carcinoma of head and neck: DAHANCA 6 and 7 randomised controlled trial. Lancet. 2003;362:933940.

11. Bourhis, J.S.N., Overgaard, J., Ang, K.K. et al, Conventional vs modified fractionated radiotherapy. meta-analysis of radiotherapy in head and necksquamous cell carcinoma: a meta-analysis based on individual patient data. Int $\mathrm{J}$ Radiat Oncol Biol Phys. 2004;S190-S191.

12. Withers H, Taylor J, Maciejewski B: The hazard of accelerated tumor clonogen repopulation during radiotherapy. Acta Oncol 27:131-146, 1988.

13. Withers H, Peters L, Taylor J, et al: Local control of carcinoma of the tonsil by radiation therapy: An analysis of patterns of fractionation in nine institutions. Int $\mathbf{J}$ Radiat Oncol Biol Phys 33:549-562, 1995.

14. Butler E, Teh B, Grant III W, et al: SMART (Simultaneous Modulated Accelerated Radiation Therapy) boost: A new accelerated fractionation schedule for the treatment of head and neck cancer with intensity modulated radiotherapy. Int J Radiat Oncol Biol Phys 45:21-32, 1999.

15. Overgaard J, Sand Hansen H, Overgaard $\mathrm{M}$, et al: Importance of overall treatment time for the outcome of radiotherapy in head and neck carcinoma: Experience from the Danish Head and Neck Cancer Study, in Kogelnik H, Sedlmayer F (eds): Sixth International Meeting on Progress in Radio-Oncology, pp 743-752. Bologna, Italy, Monduzzi Editore, 1998.

16. Skladowski K, Maciejewski B, Golen M, et al: Randomized clinical trial on 7-daycontinuous accelerated irradiation (CAIR) of head and neck cancer \pm report on 3-year 
tumour control and normal tissue toxicity. Radiother Oncol 55:101-110, 2000.

17. Jackson S, Weir L, Hay J, et al: A randomised trial of accelerated vs conventional radiotherapy in head and neck cancer. Radiother Oncol 43:39-46, 1997.

18. Knee R, Fields R, Peters LJ: Concomitant boost radiotherapy for advanced squamous cell carcinoma of the head and neck. Radiother Oncol 4:1-7, 1985.

19. Ang KK, Peters LJ, Weber RS, et al: Concomitant radiotherapy schedules in the treatment of carcinoma of the oropharynx and nasopharynx. Int $\mathbf{J}$ Radiat Oncol BiolPhys 19:1339-1345, 1990.

20. Withers RH. Dose fractionation and regeneration in $\mathrm{RT}$ for $\mathrm{Ca}$ of the oral cavity and oropharynx. Part 2 - Normal tissue responses acute and late effects. Int Jour of Radiation OncolBiol and Phys. 1990;18:101-110.

21. Kaanders JHAM, Van Daal WAJ, Hoogenraad WJ et al. Accelerated fractionation radiotherapy for laryngeal cancer, acute and late toxicity. Int. J. Rad. Oncol. Biol. And Phys. 1992;24:497.

22. Yu E, Souhami L, Guerra J et al. Accelerated fractionation in inoperable non small cell lung cancer. A phase I-II study. Cancer. 1993;71:2727.

23. Peters LJ, Ang KK, Thomas HD. Accelerated fractionation in the radiation treatment of head and neck cancer: A critical comparison of different treatment strategies. ActaOncol. 1988; (Suppl.2) 27:185-194.

24. Withers HR, Taylor IMG, Maciejewski B. The hazard of accelerated tumor clonogen repopulation during radiotherapy. Acta Oncol 1988; (Suppl.2) 27: 131-146.

25. Rishi A, Ghoshal S, Verma R, Oinam AS, Patil VM, Mohinder R et al. Comparison of concomitant boost radiotherapy against concurrent chemoradiation in locally advanced oropharyngeal cancers: a phase III randomised trial; radiotherapy and oncology. 2013;107:317-24.

26. Srivastava K, Srivastava M. Concomitant boost radiotherapy vs conventional radiotherapy in advanced oral cavity and oropharyngeal cancers. Indian journal of radiology and imaging. 2001;11:127-30.1

27. Pramod K S, Sunny K, Bhupendra k s, Mangesh K, Jitendra k v. A Prospective Study on Toxicity, Quality of Life and Local Control of Post Mastectomy External Shorter Course of Irradiation. Canc Therapy \& Oncol Int J. 2017; 5(5): 555675.

DOI: 10.19080/CTOIJ.2017.05.555675. 